\title{
Detecting forensic substances using commercially available SERS substrates and handheld Raman spectrometers
}

Hakonen, Aron; Wu, Kaiyu; Schmidt, Michael Stenbæk; Andersson, Per Ola; Boisen, Anja; Rindzevicius, Tomas

Published in:

Talanta

Link to article, DOI:

10.1016/j.talanta.2018.07.009

Publication date:

2018

Document Version

Peer reviewed version

Link back to DTU Orbit

Citation (APA):

Hakonen, A., Wu, K., Schmidt, M. S., Andersson, P. O., Boisen, A., \& Rindzevicius, T. (2018). Detecting forensic substances using commercially available SERS substrates and handheld Raman spectrometers. Talanta, 189, 649-652. https://doi.org/10.1016/j.talanta.2018.07.009

\section{General rights}

Copyright and moral rights for the publications made accessible in the public portal are retained by the authors and/or other copyright owners and it is a condition of accessing publications that users recognise and abide by the legal requirements associated with these rights.

- Users may download and print one copy of any publication from the public portal for the purpose of private study or research.

- You may not further distribute the material or use it for any profit-making activity or commercial gain

- You may freely distribute the URL identifying the publication in the public portal 


\section{Author's Accepted Manuscript}

Detecting forensic substances using commercially available SERS substrates and handheld Raman spectrometers

Aron Hakonen, Kaiyu Wu, Michael StenbækSchmidt, Per Ola Andersson, Anja Boisen, Tomas Rindzevicius

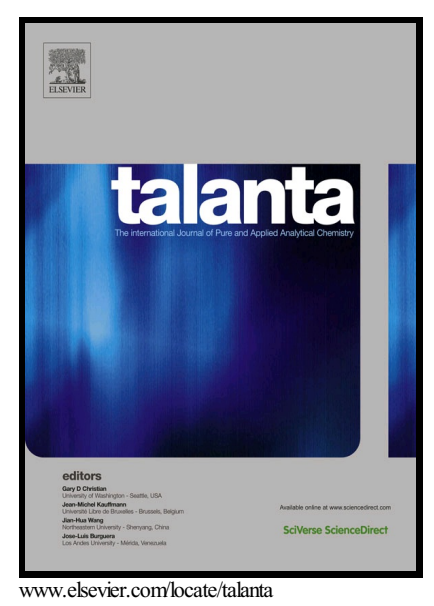

PII: $\quad$ S0039-9140(18)30701-X

DOI: $\quad$ https://doi.org/10.1016/j.talanta.2018.07.009

Reference: TAL18838

To appear in: Talanta

Received date: 6 June 2018

Revised date: 2 July 2018

Accepted date: 5 July 2018

Cite this article as: Aron Hakonen, Kaiyu Wu, Michael Stenbæk-Schmidt, Per Ola Andersson, Anja Boisen and Tomas Rindzevicius, Detecting forensic substances using commercially available SERS substrates and handheld Raman spectrometers, Talanta, https://doi.org/10.1016/j.talanta.2018.07.009

This is a PDF file of an unedited manuscript that has been accepted for publication. As a service to our customers we are providing this early version of the manuscript. The manuscript will undergo copyediting, typesetting, and review of the resulting galley proof before it is published in its final citable form. Please note that during the production process errors may be discovered which could affect the content, and all legal disclaimers that apply to the journal pertain. 


\title{
Detecting forensic substances using commercially available SERS sub- strates and handheld Raman spectrometers
}

\author{
Aron Hakonen, ${ }^{\text {a }}$ Kaiyu Wu, ${ }^{\mathrm{b}}$ Michael Stenbæk-Schmidt, ${ }^{\mathrm{b}}$ Per Ola Andersson, ${ }^{\mathrm{c}, \mathrm{d}}$ Anja Boisen ${ }^{\mathrm{b}}$ and Tomas \\ Rindzevicius ${ }^{\mathrm{b}}$ \\ ${ }^{a}$ Sensor Visions AB, Legendgatan 116, 42255 Hisings Backa, Sweden. \\ ${ }^{\mathrm{b}}$ DTU Nanotech, Technical University of Denmark, Department of Micro- and Nanotechnology, Ørsteds Plads, Building 345 \\ east, 2800 Kgs. Lyngby \\ 'Swedish Defense Research Agency FOI, CBRN Defence \& Security, SE-90182 Umeå, Sweden. \\ ${ }^{\mathrm{d} D e p a r t m e n t}$ of Engineering Sciences, Uppsala University, P.O. Box 534, SE-751 21 Uppsala, Sweden.
}

\section{ABSTRACT:}

Ultra-sensitive in-field measurements of most forensic substances still today remain a challenge for first responders and forensic investigators. Handheld Raman spectroscopy equipment is getting more and more routinely used in the field for evidence collection, however, restricted to measurements of pure or high concentration samples. Here, surface-enhanced Raman scattering (SERS) sensing of common forensic substances with commercially available SERS substrates and handheld spectrometers, have been investigated. 3D-Finite Element Method (FEM) and Discrete Fourier Transformation (DFT) simulations were used to show the high SERS enhancement of the nanostructures and to interpret the detection of the substances. The forensic generality and high performance of the analytical method were demonstrated by explicit detection of close to unprecedented amounts, down to femtograms, of Cyclosarin, RDX, Amphetamine and Picric acid. Implications are ultra-sensitive in-field SERS detection of these substances with commercial equipment .

Graphical abstract

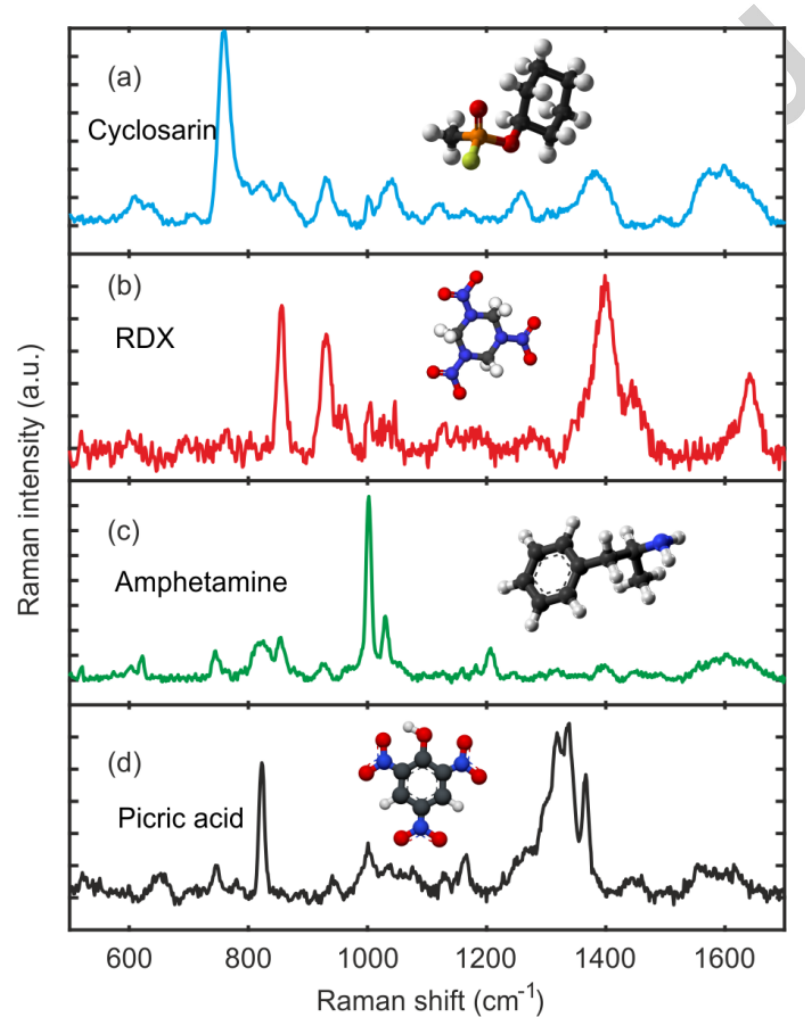


Keywords: SERS; Raman; forensic detection; chemical warfare agents; explosives; narcotics

One of the most promising techniques for future ultra-sensitive in-field forensic detection may be surface-enhanced Raman scattering (SERS). ${ }^{1-10}$ SERS based detection displays highly attractive properties in term of sensitivity, speed, cost, multiplexing and portability. ${ }^{10-15}$ For in-field forensic chemical detection one of the most important parameters is the portability, preferably it should be in the form of a small and robust handheld device for convenient in-situ measurements. Handheld Raman scattering spectrometers and commercial availability of such instruments are essential for promoting and advancing in-field applications. ${ }^{13}$ Portable and quick on-site identification of target substances is becoming a reality with progressively better, smaller and cheaper Raman instruments. Prices for such instruments starts roughly at 10000 US\$. Nowadays, reports utilizing commercial handheld spectrometers are becoming more and more common for various constituents such as: amino acids, ${ }^{16}$ fungicides, ${ }^{17}$ pesticides, ${ }^{18}$ food elements, ${ }^{19,20}$ meat quality, ${ }^{21}$ cannabinoids ${ }^{22}$ and viruses. ${ }^{23}$

Fig. 1 Profile SEM image of the Ag nanopillar SERS substrates (top). The pillars are roughly $400 \mathrm{~nm}$ in height. Schematic picture of the structure with a droplet and water capillaries (left). SEM image of nanoparticle clusters that have been pulled together by the elastocapillarity (middle). Cartoon demonstrating how the electromagnetic fields around two pulled together nanopillars can look like (right).

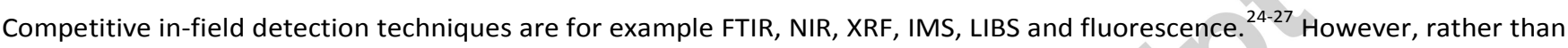
seeing these techniques as competition one could view them as complementary and as tools for cross validation directly insitu. Ideally two or more of them could be incorporated in the same instrument.

Figure 1 illustrates the SERS substrates used in this study. These, recently commercially available (Silmeco ${ }^{\mathrm{TM}}$ ), $\mathrm{Au}$ and $\mathrm{Ag}$ nanopillar substrates have been developed, optimized and characterized over the last few years. ${ }^{28,29} \mathrm{~A}$ guiding average price per sample is 10 US\$, when $4-5$ sample droplets are analysed on each substrate, which could be even further reduced by optimized sample droplet management. Results on these substrates have demonstrated remarkable characteristics and performance, to mention a few highlights; flexibility for hot-spots, ${ }^{28,29}$ superhydrophobicity, $^{30}$ high adhesion, $^{30}$ elasto-capillarity $^{31}$ and record detection of threat molecules VX, Tabun and Picric acid. ${ }^{30,31}$

Fig. 2 3D FEM simulation of Ag capped Si nanopillar clusters; (a) cross-sectional field distribution of a nanopillar dimer, (b) and (c) side-view and top-view field distribution on the surface of a nanopillar trimer; scale bar: $50 \mathrm{~nm}$; the minimum gap distance between adjacent nanopillars is $\sim 3 \mathrm{~nm}$; the excitation wavelength is $780 \mathrm{~nm}$. More details in supporting information.

Some of the properties are really essential for the superior SERS functionality of the substrates, for example the flexibility and potential to generate SERS hot-spots. ${ }^{28}$ Also, the high adhesion and elasto-capillarity are crucial as they make it possible for the analyte molecules to end up in the hot-spots. ${ }^{31}$

To demonstrate the high enhancement of the nanopillar substrate and to illustrate its SERS hot spots, electrical field enhancements near a dimer and a trimer of nanopillars are 3D FEM simulated, see Figure 2. The simulation reveals that under a $780 \mathrm{~nm}$ excitation the nanopillar structures efficiently support the following localized surface plasmon resonance modes: (i) the hybrid gap mode, ${ }^{32}$ which generates electromagnetic hot spots in the gap junctions between adjacent Ag caps, and (ii) the cavity mode, which generates electromagnetic hot spots near the bottom of the $\mathrm{Ag}$ caps. The simulation also reveals that the maximum field enhancement occurs in the gap junctions between adjacent $\mathrm{Ag}$ caps. The calculated maximum electromagnetic SERS enhancement factor is $1.7 \times 10^{10}$ and $1.0 \times 10^{10}$ for a nanopillar dimer and trimer, respectively. Other studies have shown that maximum SERS enhancement factors are of the order of $10^{10}$ in typical SERS conditions and are at most of the order of $10^{12}$ in the best possible conditions. ${ }^{33-35}$ To achieve single molecule detection, a SERS enhancement factor above $10^{9}$ is necessary. ${ }^{36}$ The experimentally measured average SERS enhancement factor for the utilized nanopillar substrate is $>10^{8},{ }^{29}$ which is among the best across all the state-of-the-art SERS substrates whose average SERS enhancement factors fall typically in the range of $10^{6}-10^{8} .{ }^{37-39}$

To further promote these structures as general forensic SERS substrates for portable in-situ measurements, low level measurements of four substances were made on the handheld First Defender RMX. However, not in the truly handheld mode but rather semi-fixed as previously utilized and described. ${ }^{30,35}$

The new substances were Cyclosarin (GF), RDX and Amphetamine, also Picric acid is shown which previously was demonstrated on the Serstech 100 Indicator. Where

Fig. 3 Portable First defender SERS spectrum of a) Cyclosarin ( $2 \mu \mathrm{L}, 20 \mu \mathrm{g} / \mathrm{mL})$. b) RDX (2 $\mu \mathrm{L}, 2 \mathrm{ng} / \mathrm{mL})$. c) Amphetamine ( $2 \mu \mathrm{L}, 2$ $\mathrm{ng} / \mathrm{mL}$ ). d) Picric acid $\left(2 \mu \mathrm{L}, 0.4 \mathrm{ng} / \mathrm{mL}\right.$ ). All on Silmeco ${ }^{\mathrm{TM}} \mathrm{Ag}$ substrates. Experimental details can be found in the supporting information. 
Cyclosarin represents nerve gases or chemical warfare agents. Nerve gases are generally difficult to measure with SERS and very little is published. ${ }^{13,30} \mathrm{RDX}$ is another high nitro explosive, however, lacking conjugated system which leads to a much smaller Raman cross-section. Also, common "street drug" and Breaking bad drug relative Amphetamine was tested.

For Cyclosarin we found no comparative SERS studies which are comprehensible due to its difficult structure as well as highly restricted use and accessibility. Figure 3a shows a SERS spectrum from a $2 \mu \mathrm{L}$ droplet of $20 \mu \mathrm{g} / \mathrm{mL} \mathrm{GF}$ (total amount 40 $\mathrm{ng}$ ). The major peak at $760 \mathrm{~cm}^{-1}$ corresponds well with major normal Raman peak at $752 \mathrm{~cm}^{-1}$ published by Christesen et al., and the peak assignment was P-C stretch vibration. ${ }^{40}$ Additional nearby and likely corresponding peaks in the experimental spectrum (Fig. 3a) are at 825 and $856 \mathrm{~cm}^{-1}$ ( 830 and 858 in Christesen et al.) assigned to $\mathrm{PO}_{2}$ stretch and P-F stretch, respectively. ${ }^{40}$ Further, corresponding are a $\mathrm{P}=\mathrm{O}$ assigned peak at $1260(1265) \mathrm{cm}^{-1}$, and an unassigned group of peaks at $1000-1120$ $\mathrm{cm}^{-1} \cdot 40$

In figure 3b SERS spectrum from an evaporated $2 \mu \mathrm{L} 2 \mathrm{ng} / \mathrm{mL}$ (total amount of $18 \mathrm{fmol}$ or $4 \mathrm{pg}$ ) droplet of RDX is displayed. Record RDX detection according to a recent review, ${ }^{13}$ is $0.5 \mathrm{pM}^{41}$ in concentration and $20 \mathrm{pg}^{42}$ in amount. The study by Kanchanapally et al. ${ }^{41}$ demonstrated a major RDX peak at $870 \mathrm{~cm}^{-1}$ with peak assignment to $\mathrm{C}-\mathrm{N}-\mathrm{C}$ ring breathing, which correlates to our 855 peak. That study also showed a major peak at $930 \mathrm{~cm}^{-1}$, closely related to our 932 peak, assigned to ring stretching and $\mathrm{N}-\mathrm{O}$ deformation. Remaining major bands in Fig. 4b 1400 and 1642 may be related to red-shifted $\mathrm{NO}_{2}$ symmetric and asymmetric stretch vibration, respectively.

Amphetamine SERS spectrum can be seen in Fig. 3c. Main peak is at $1002 \mathrm{~cm}^{-1}$, i.e. near $1000 \mathrm{~cm}^{-1}$ as frequently shown. ${ }^{43-45}$ Though, many peaks are present despite the low concentration/amount ( $2 \mathrm{ng} / \mathrm{mL}, 2 \mu \mathrm{L})$, of which many peaks corresponds to literature, e.g. 604, 622, 745, 820, 854, 927, 1002, 1030, 1159, 1182 and $1207 \mathrm{~cm}^{-1}$ are all near Faulds et al's peaks. ${ }^{43}$ Further, for some peak assignments the major 1002 peak is assigned to aromatic ring breathing. The $622 \mathrm{~cm}^{-1}$ peak comes from in plane aromatic ring deformation, 1033 from in plane $\mathrm{C}-\mathrm{H}$ deformation, and 1207 relates to $\mathrm{C}_{6} \mathrm{H}_{5}-\mathrm{C}$ vibration. ${ }^{45}$ Equally low SERS detection of amphetamine as in the present study $(2 \mathrm{ng} / \mathrm{mL}, 2 \mu \mathrm{L})$ could not be found within present literature, for example in the above mentioned article $(135 \mu \mathrm{g} / \mathrm{mL}, 25 \mu \mathrm{L})$ was used. ${ }^{43}$

Picric acid is a high explosive that has had a revival as an interesting analyte over the last few years. ${ }^{46-48}$ The SERS spectrum of low amount Picric acid in Fig. 3d clearly displays previously shown Raman signature, with major single peak at $823 \mathrm{~cm}^{-1}$, as earlier demonstrated and used for quantification. ${ }^{31}$ A group of large peaks are located at $1300 \mathrm{~cm}^{-1}$ and just above. ${ }^{31}$ Major peaks maxima's at 820 and $1332 \mathrm{~cm}^{-1}$ was assigned to vibrational modes of the $\mathrm{NO}_{2}$-group. ${ }^{31}$ A record calculated SERS detection limit of $0.02 \mathrm{ng} / \mathrm{mL}$ picric acid has been demonstrated. ${ }^{31}$ This is a calculated detection limit that is below our explicitly detected $0.4 \mathrm{ng} / \mathrm{mL}$, however, at this higher concentration the signal to noise ratio was on the same order of magnitude $(\mathrm{S} / \mathrm{N}=$ 100 ) indicating that similar detection is possible. The detection capabilities for the four analytes are summarized in Table 1.

DFT simulations of the Raman spectra of these forensic molecules demonstrate many similarities, but also in some cases differences (Fig. 4). Peak assignment tables and detailed correlations with the experimental data can be found in supporting information tables S1 - S4. Also, other simulation and experimental details can be found in the supporting information.

Fig. 4 DFT simulated spectras of Cyclosarin, RDX, Amphetamine and Picric acid. Insets show the modelled molecular structures. More details in supporting information.

Table 1. SERS detection limits* found in literature compared with present study.

\begin{tabular}{|l|c|c|}
\hline Analyte & Literature & Present study \\
\hline Cyclosarin & $-* *$ & $40 \mathrm{ng}$ \\
\hline RDX & $20 \mathrm{pg}^{42}$ & $4 \mathrm{pg}$ \\
\hline Amphetamine & $3 \mu \mathrm{g}^{43}$ & $4 \mathrm{pg}$ \\
\hline Picric acid & $0.04 \mathrm{pg}^{31}$ & $0.8 \mathrm{pg}$ \\
\hline
\end{tabular}




\section{Conclusions}

Within this study, portable surface-enhanced Raman scattering (SERS) sensing of common forensic substances on commecially available SERS substrates with commercial handheld spectrometers, have been demonstrated. Forensic generality and high performance of the substrates and high applicability of the analytical method are demonstrated by explicit detection of close to unprecedented amounts, down to femtograms, of Cyclosarin, RDX, Amphetamine and Picric acid. In addition, new 3-D FEM and DFT simulations have been used to explain and understand the photonics of the system leading to vast SERS enhancements. Implications from this study may be the possibility of ultra-sensitive in-field SERS detection of forensic substances with commercial equipment.

\section{Conflicts of interest}

T. Rindzevicius, A. Boisen and M. S. Schmidt are co-founders of the Silmeco ApS company.

\section{ACKNOWLEDGMENT}

This research was financially supported by the IDUN Center of Excellence funded by the Danish National Research Foundation (grant no. DNRF122) and the Villum Fonden (Grant No. 9301).

\section{REFERENCES}

1. Li, J. F., et al., Nature (2010) 464 (7287), 392

2. $\quad$ Dasary, S. S. R., et al., J. Am. Chem. Soc. (2009) 131 (38), 13806

3. $\quad$ Chou, A., et al., Nanoscale (2012) 4 (23), 7419

4. Demeritte, T., et al., Analyst (2012) 137 (21), 5041

5. Sajanlal, P. R., and Pradeep, T., Nanoscale (2012) 4 (11), 3427

6. Zhou, H. B., et al., Anal. Chem. (2011) 83 (18), 6913

7. Holthoff, E. L., et al., Sensors (2011) 11 (3), 2700

8. Liu, X. J., et al., Talanta (2011) 83 (3), 1023

9. $\quad$ Stuart, D. A., et al., Analyst (2006) 131 (4), 568

10. Yan, F., and Vo-Dinh, T., Sens. Actuator B-Chem. (2007) 121 (1), 61

11. Lee, S., et al., Anal. Chim. Acta (2007) 590 (2), 139

12. Halvorson, R. A., and Vikesland, P. J., Environ. Sci. Technol. (2010) 44 (20), 7749

13. Hakonen, A., et al., Anal. Chim. Acta (2015) 893, 1

14. Pilot, R., et al., Surface-Enhanced Raman Spectroscopy: Principles, Substrates, and Applications. In Metal Nanoparticles and Clusters: Advances in Synthesis, Properties and Applications, Deepak, F. L., (ed.) Springer International Publishing, Cham, (2018), pp 89

15. Müller, C., et al., Talanta (2014) 130, 108

16. Jehlicka, J., et al., Anal. Bioanal. Chem. (2010) 397 (7), 2753

17. Zheng, J., et al., Analyst (2013) 138 (23), 7075

18. Zheng, J., et al., Talanta (2014) 129 (0), 79

19. Radu, A. I., et al., Talanta (2016) 160, 289

20. Pilot, R., Journal of Raman Spectroscopy (2018) 49 (6), 954

21. Sowoidnich, K., et al., Vib. Spectrosc. (2012) 62, 70

22. Mostowtt, T., and McCord, B., Talanta (2017) 164, 396

23. Song, C. Y., et al., Chemical, Biological, Radiological, Nuclear, and Explosives (Cbrne) Sensing Xiii (2012) 8358, 7

24. Hakonen, A., et al., Anal. Chim. Acta (2013) 786, 1

25. Hakonen, A., et al., Analyst (2014) 139 (14), 3524

26. Meier, R. J., et al., Anal. Chem. (2014) 86 (11), 5535 
27. Hakonen, A., et al., Talanta (2010) 81 (4-5), 1393

28. Schmidt, M. S., et al., Adv. Mater. (2012) 24 (10), OP11

29. Wu, K., et al., J. Phys. Chem. C (2015) 119 (4), 2053

30. Hakonen, A., et al., Nanoscale (2016) 8 (3), 1305

31. Hakonen, A., et al., ACS Sens. (2017) 2 (2), 198

32. Wu, K., et al., Opt. Express (2015) 23 (10), 12965

33. Le Ru, E. C., et al., The Journal of Physical Chemistry C (2007) 111 (37), 13794

34. Lim, D.-K., et al., Nature Materials (2009) 9, 60

35. Hakonen, A., et al., Nanoscale (2015) 7 (21), 9405

36. Ru, E. C. L., and Etchegoin, P. G., Annual Review of Physical Chemistry (2012) 63 (1), 65

37. Sharma, B., et al., MRS Bulletin (2013) 38 (8), 615

38. Reyer, A., et al., ACS Applied Materials \& Interfaces (2017) 9 (30), 25445

39. Li, T., et al., ACS Applied Materials \& Interfaces (2016) 8 (24), 15668

40. Christesen, S. D., et al., Appl. Spectrosc. (2008) 62 (10), 1078

41. Kanchanapally, R., et al., J. Phys. Chem. C (2014) 118 (13), 7070

42. Almaviva, S., et al., Journal of Raman Spectroscopy (2014) 45 (1), 41

43. Faulds, K., et al., Analyst (2002) 127 (2), 282

44. Inscore, F., et al., Appl. Spectrosc. (2011) 65 (9), 1004

45. Massarini, E., et al., Sens. Actuator B-Chem. (2015) 207, 437

46. Tanwar, A. S., et al., ACS Sens. (2016) 1 (8), 1070

47. Huynh, T.-P., et al., ACS Sens. (2016) 1 (6), 636

48. Gogoi, B., et al., Journal of Materials Chemistry C (2015) 3 (42), 11081

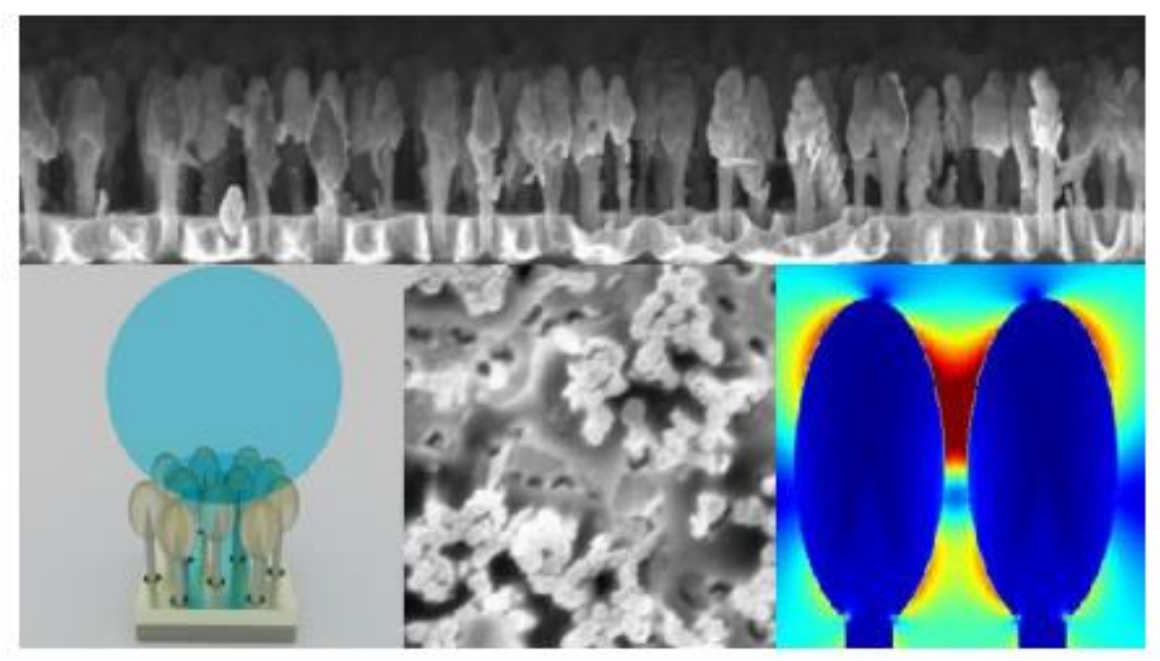



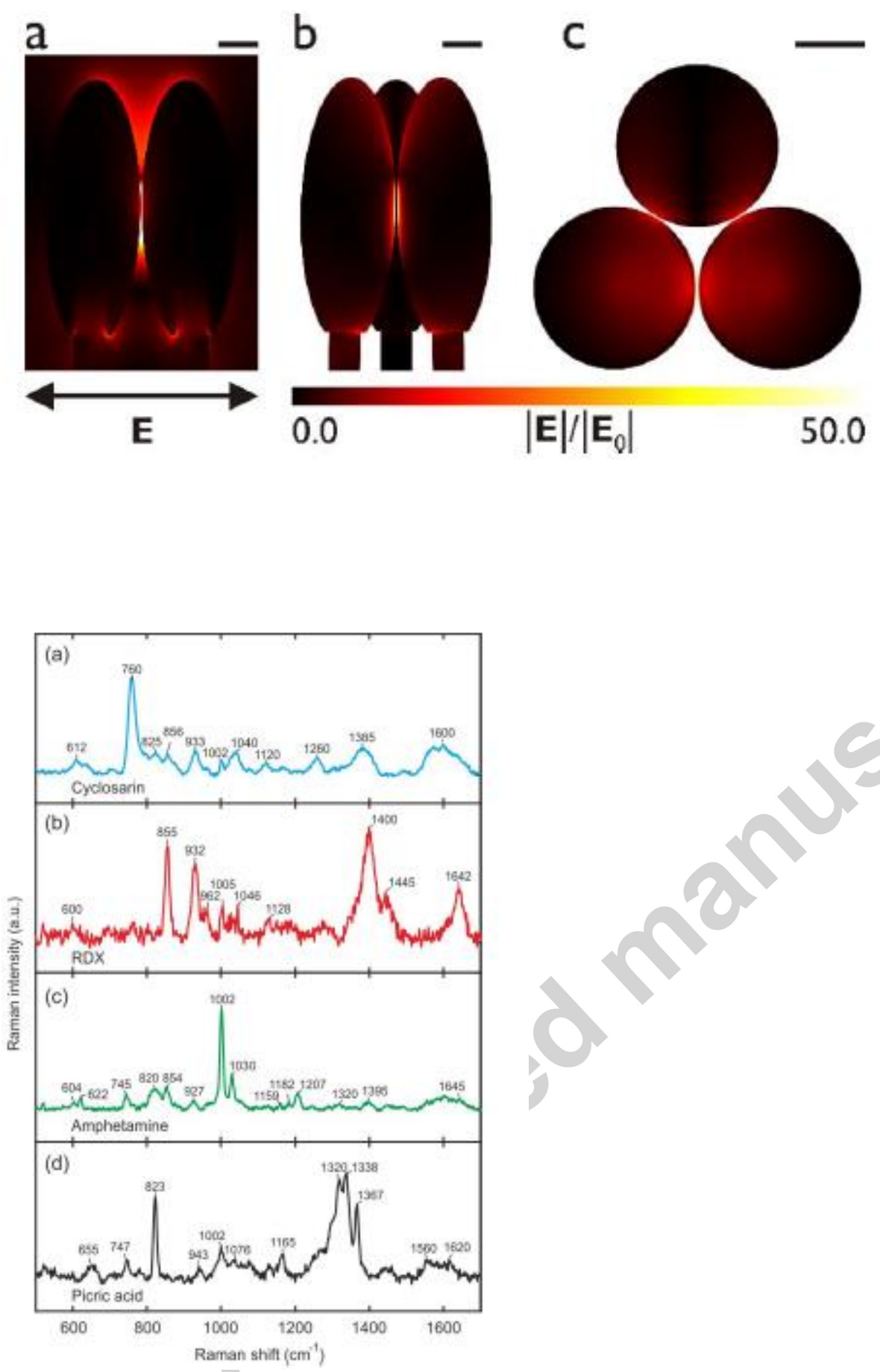


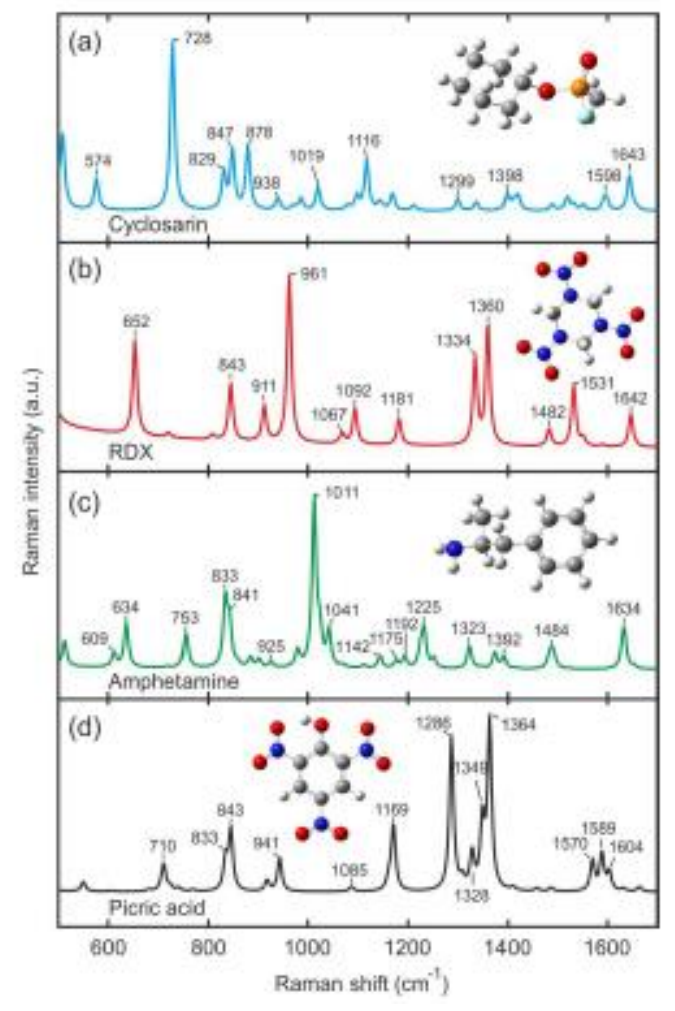

\section{Highlights}

- Close to unprecedented detection of nerve gases, explosives and narcotics are presented

- Simulations are performed to support and interpret results

- Comprehensive peak-assignment tables are included in the supplementary material

- Implications are ultra-sensitive in-field SERS detection of these substances with commercial equipment 